\title{
Limitação da produtividade pela deficiência de boro nas culturas da soja, milho, feijão e café
}

Engenheiro Agrônomo - Universidade Estadual Paulista (Unesp), Faculdade de Ciências Agrárias e Veterinárias, Jaboticabal, Especialista em Manejo do Solo (ESALQ), e-mail: rmagrotomicioli@gmail.com.

Fábio Tiraboschi Leal (D)

Doutor em Agronomia (Produção Vegetal) - Universidade Estadual Paulista (Unesp), Faculdade de Ciências Agrárias e Veterinárias, Jaboticabal, lealft@bol.com.br.

Anderson Prates Coelho iD Mestre em Agronomia (Produção Vegetal) - Universidade Estadual Paulista (Unesp), Faculdade de Ciências Agrárias e Veterinárias, Jaboticabal, anderson_100ssp@hotmail.com.

\section{RESUMO}

O boro é um dos micronutrientes que mais limita a produtividade das culturas nas condições dos solos brasileiros. Este elemento participa de funções ligadas ao enraizamento das plantas até o enchimento de grãos, gerando elevada responsividade das culturas em solos com médios e baixos teores. Os principais fatores que contribuem para os baixos teores de boro no solo são a lixiviação que o nutriente pode sofrer, baixo valor do $\mathrm{pH}$ do solo, baixos teores de matéria orgânica e a reposição do micronutriente ao longo dos cultivos. Tomadas de decisões no manejo que visam principalmente o aporte de matéria orgânica no sistema impactam de forma positiva nos teores de boro no solo, além de melhorias tanto nos parâmetros químicos, físicos e biológicos dos solos. No mercado existem diversas fontes de boro para a utilização na agricultura e cada fonte apresenta comportamento distinto, para a forma de aplicação, perdas por lixiviação e solubilidade, diferindo a resposta para os diferentes tipos de solo e cultura. Este trabalho visa levantar informações sobre as estratégias para o manejo nutricional com boro, escolha de fontes mais adequadas para a nutrição das plantas, quantificar perdas de lixiviação em função da fonte utilizada e, principalmente, dar subsídios para melhorias no manejo com boro para as culturas da soja, milho, feijão e café.

Palavras-chave: Lixiviação; Fontes; Textura do solo.

\section{Limitation of productivity by boron deficiency in soybean, corn, beans and coffee crops}

\section{ABSTRACT}

Boron is one of the micronutrients that most limits crop productivity under Brazilian soil conditions. This element participates in functions linked to the rooting of plants until the filling of grains, generating high responsiveness of crops in soils with medium and low levels. The main factors that contribute to the low levels of boron in the soil are the leaching that the nutrient can suffer, low $\mathrm{pH}$ value of the soil, low levels of organic matter and the replacement of micronutrient throughout the crops. Management decision-making aimed mainly at the supply of organic matter in the system has a positive impact on soil boron levels, in addition to improvements in the chemical, physical and biological parameters of the soil. There are several sources of boron on the market for use in agriculture and each source has different behaviors, for the form of application, losses by leaching and solubility, differing the response for different types of soil and culture. This work aims to gather information on the strategies for the nutritional management with boron, to choose more suitable sources for plant nutrition, to 
quantify leachate losses according to the source used and, mainly, to provide subsidies for improvements in the management with boron for the crops of soybean, corn, beans and coffee.

Keywords: Leaching; Sources; Soil texture.

\title{
Limitación de la productividad debido a la deficiência de boro em cultivos de soja, maíz, frijol y café
}

\begin{abstract}
RESUMEN
El boro es uno de los micronutrientes que más limita la productividad de los cultivos en las condiciones del suelo brasileño. Este elemento participa en funciones vinculadas al enraizamiento de las plantas hasta el llenado de granos, generando una alta capacidad de respuesta de los cultivos en suelos con niveles medios y bajos. Los principales factores que contribuyen a los bajos niveles de boro en el suelo son la lixiviación que puede sufrir el nutriente, el bajo valor del $\mathrm{pH}$ del suelo, los bajos niveles de materia orgánica y el reemplazo de micronutrientes en todos los cultivos. La toma de decisiones de gestión dirigida principalmente al suministro de materia orgánica en el sistema tiene un impacto positivo en los niveles de boro en el suelo, además de mejoras en los parámetros químicos, físicos y biológicos del suelo. En el mercado existen várias fuentes de boro para su uso en la agricultura y cada fuente tiene comportamiento diferente, en cuanto a la forma de aplicación, pérdidas por lixiviación y solubilidad, que difieren en la respuesta para diferentes tipos de suelo y cultivo. Este trabajo tiene como objetivo recopilar información sobre las estrategias para el manejo nutricional con boro, elegir fuentes más adecuadas para la nutrición de las plantas, cuantificar las pérdidas de lixiviados de acuerdo con la fuente utilizada $y$, principalmente, proporcionar subsidios para mejoras en el manejo del boro para los cultivos. soja, maíz, frijoles y café.
\end{abstract}

Palabras clave: Lixiviación; Fuentes; Textura del suelo.

\section{Introdução}

O micronutriente boro (B) é um fator limitante para as áreas agrícolas e sua correção nos solos brasileiros é de extrema importância para o aumento da produtividade (SANTINI et al., 2015). Em virtude de diversos trabalhos que comprovam ser um nutriente imóvel no floema, exceto para algumas espécies de plantas como a macieira, cerejeira e ameixeira (HU,1997), a aplicação via solo acaba sendo a forma mais eficiente de nutrição das plantas com esse nutriente.

As funções que este nutriente desempenha no metabolismo vegetal vão desde a formação das raízes, devido a atuação na divisão celular, até o enchimento dos grãos e diminuição da formação de calose no floema (CAKMAK, 2016, apud YAMADA, 2016; FANCELLI, 2010; LOUÉ, 1993; ORLANDO FILHO et al., 2001).

A utilização do $B$, especialmente para grãos e café, é bastante importante, e, devido sua dinâmica no solo, o conhecimento adequado sobre 
o manejo desse nutriente reflete positivamente na produtividade e qualidade dos produtos colhidos (FLORES et al., 2018; SAKO et al., 2016).

Visando a correção de boro no solo, entender os fatores que afetam a dinâmica do micronutriente reduz as perdas por lixiviação e favorece o aumento dos teores desse elemento no solo. A escolha da fonte adequada de $B$, considerando as características do sistema de produção como: textura, teor de matéria orgânica, tipo de cultura, histórico de precipitação da área e $\mathrm{pH}$, auxilia na compreensão e tomada de decisão dentro das propriedades agrícolas.

Esta revisão visa abordar de forma objetiva temas importantes sobre o uso de B, com o intuito de gerar informações sobre a correção dos teores do elemento no solo e nutrição adequada das plantas de soja, milho, feijão e café.

\section{Desenvolvimento}

\section{A importância do boro no metabolismo vegetal}

De acordo com Arnon e Stout (1939) o elemento para ser considerado essencial necessita atender critérios diretos e indiretos (PETRA, 2012). No critério direto, o elemento deve participar de algum composto ou reação sem a qual a planta não vive, como por exemplo, o magnésio, que está presente como átomo central da molécula da clorofila essencial ao processo de fotossíntese dos vegetais.

Logo para os critérios classificados como indiretos, destaca-se: I) na ausência do elemento a planta não completa seu ciclo de vida, II) - o elemento não pode ser substituído por nenhum outro, III) - o elemento possui efeito direto na vida da planta e não exerce função apenas de neutralizar os efeitos químicos, físicos e biológicos desfavoráveis aos vegetais.

O boro foi considerado até meados da década de 1990 essencial apenas pelo critério indireto (MALAVOLTA, 2006). Com uma pesquisa realizada no Japão em 1996, foi comprovado em plantas de nabo (Brassica 
rapa L.) que a parede celular dessa espécie apresentava um polissacarídeo péctico contendo boro, a boro ramnogalacturonana-II (RG-II-B), passando o elemento a atender o critério direto da essencialidade (KOBAYASHI et al., 1997).

De acordo com Malavolta et al. (1997), pode-se classificar o nutriente de acordo com a função exercida na planta, sendo classificado como: I) - estrutural quando este participa de um composto orgânico da planta, II) - constituinte de enzimas, quando faz parte da enzima, III) ativador enzimático quando participa ativando e inibindo enzimas, afetando a velocidade de reações no metabolismo vegetal.

O B é um elemento que atua na constituição da parede celular, garantindo melhor organização de substâncias cimentantes como pectinas, celuloses, hemiceluloses e precursores de lignina. Um trabalho que ilustra essa função é o de Moraes et al. (2002), demonstrando a participação do boro na deposição de substâncias cimentantes em células de seringueira.

Em leguminosas como soja e feijão, a falta de B poderá afetar a parede celular dos nódulos presentes nas raízes, permitindo a entrada de oxigênio para o interior dos nódulos, diminuindo o processo de fixação biológica de nitrogênio (LUKASZEWSKI; BLEVINS, 1996).

De acordo com uma pesquisa realizada por Cakmak et al. (1995), o suprimento de B para as plantas reduziu o extravasamento celular de potássio, sacarose, compostos fenólicos e aminoácidos em folhas de girassol, demonstrando a importância que o boro apresenta na integridade da membrana plasmática (Tabela 1).

O boro participa diretamente do processo de divisão celular, tanto da parte aérea como do sistema radicular. Acredita-se que o aumento dos níveis de auxina com o acréscimo de $\mathrm{B}$, favoreça o processo de divisão celular (COHEN; LEPPER, 1977). O crescimento de raízes de soja e milho pode ser verificado conforme a pesquisa realizada por Cakmak (1995), em que a soja apresentou maior sensibilidade à deficiência desse micronutriente quando comparado ao milho. 
Tabela 1. Concentração foliar de B em girassol e efeito no vazamento celular de potássio, sacarose, fenólicos e aminoácidos.

\begin{tabular}{cccccc}
\hline Suprimento B & B & \multicolumn{4}{c}{ Vazamento $\left(\mu \mathrm{g} \mathrm{g}^{-1} \mathrm{PF}^{2} \mathrm{~h}^{-1}\right)$} \\
\hline$\mu \mathrm{M}$ & $\mu \mathrm{g} \mathrm{g}^{-1} \mathrm{PS}$ & $\mathrm{K}+$ & Sacarose & Fenólicos & Aminoácidos \\
\hline 0,01 & 4,7 & 630 & 900 & 79 & 163 \\
0,20 & 11,8 & 390 & 440 & 72 & 122 \\
1,00 & 16,7 & 52 & 70 & 17 & 33 \\
20,00 & 37,7 & 18 & 20 & 13 & 23 \\
\hline
\end{tabular}

$\mathrm{PS}=$ Peso seco, PF $2 h^{-1}=$ Peso fresco após 2 horas; Fonte: Cakmak et al. (1995).

$\mathrm{Na}$ redução do estresse, o B possui ação em diminuir os efeitos negativos do alumínio sobre o crescimento do sistema radicular, além de aumentar a produção de substâncias de defesa (RIAZ et al.,2018).

$\mathrm{Na}$ fase reprodutiva, o B desempenha importante papel na germinação do grão de pólen e desenvolvimento do tubo polínico (MENGEL; KIRKBY, 1987; PRADO, 2008). Na cultura da soja, a aplicação de B via foliar em solos de várzea do Tocantins, no estádio fenológico $R_{2}$ resultou em um aumento de $12 \%$ no número de vagens por planta (VARANDA et al., 2018).

Segundo Bruns (2017), em um experimento avaliando doses de B via foliar nos estádios fenológicos $R_{3}$ e $R_{5.1}$ para a soja, não foi encontrado resultado com diferença estatística na produtividade da soja com a aplicação de $B$ via foliar na fase reprodutiva, em virtude do teor elevado de B no solo e da textura muito argilosa.

Em trabalho realizado por Costa et al. (2014), obteve-se resultado positivo na produtividade do feijoeiro com a utilização da aplicação de B via foliar, obtendo rendimento na produtividade $24 \%$ superior em relação à testemunha, aplicado na fase reprodutiva.

Para o cafeeiro, ocorreu aumento na produção de café cereja por planta, quando o B foi aplicado via solo na forma de ulexita, obtendo aumento de $18 \%$ na produção de café cereja planta ${ }^{-1}$, quando utilizada a dose de 3,94 $\mathrm{kg} \mathrm{ha}^{-1}$ de B (ZABINI; BARBOSA, 2008). 
De acordo com Fancelli (2010), a aplicação de B via foliar próximo do momento da emissão do pendão do milho, resulta em melhor polinização das plantas e maior número de grãos por espiga.

Em relação ao transporte de carboidratos, o B apresenta a capacidade de se ligar aos açúcares, formando um borato-açúcar ionizável, facilitando o transporte de carboidratos para regiões de drenos das plantas (GAUCH; DUGGER JÚNIOR, 1953; ORLANDO FILHO et al., 2001). A deficiência de $B$ acarreta maior produção de calose nos vasos do floema, obstruindo o transporte de carboidratos (LOUÉ, 1993).

Deficiência de boro nas culturas da soja, milho, feijão e café e seu impacto na produtividade

A deficiência de B para as culturas ocorre nas folhas novas, pelo simples fato desse nutriente ser imóvel no floema. Na cultura da soja, os sintomas típicos são folhas novas com "encarquilhamento" e pontos necróticos, além de queda de botões florais e menor número de grãos nas vagens (RERKASEM et al., 1993). Esses sintomas podem ser observados em Hansel e Oliveira (2016) e Laborsolo (2015).

Na cultura da soja, a deficiência desse nutriente pode prejudicar a produtividade de grãos, uma vez que Santini et al. (2015) constataram aumento de produtividade de mais de $15 \%$ com a aplicação desse nutriente.

$\mathrm{Na}$ cultura do milho, as plantas apresentam sintomas em folhas novas, com manchas brancas ou amareladas, formando vincos (elevações nos tecidos jovens), fazendo com que, nos casos de deficiência aguda, as folhas novas fiquem retorcidas e quebradiças (MOZAFAR, 2008). Além disso, verifica-se má formação de grãos nas espigas em decorrência da deficiência de B (FANCELLI, 2010; LABORSOLO, 2015).

De acordo com Nogueira (2016), ocorreu um aumento médio de $8,52 \%$ na produtividade do milho utilizando $1,0 \mathrm{~kg} \mathrm{ha}^{-1}$ de $\mathrm{B}$ no sulco de semeadura. 
$\mathrm{Na}$ cultura do feijão, a deficiência de B leva a um menor crescimento das plantas, ocorrendo encurtamento dos internódios, as folhas ficam com coloração verde escuro e as folhas jovens ficam malformadas no ápice, levando a morte do meristema apical (EMBRAPA, 1996; OLIVEIRA et al., 1996). Os ramos têm seu tamanho reduzido e as plantas produzem poucas flores e vagens (OLIVEIRA et al., 1996).

Em um estudo realizado por Flores et al. (2018) o uso de B na forma de bórax e FTE BR 12 promoveu um aumento da produtividade de $25 \%$ e $12,5 \%$, respectivamente, na cultura do feijão.

Para a cultura do café, a deficiência de $\mathrm{B}$ leva à clorose em folhas novas, podendo evoluir para a necrose, ocorrência de morte das gemas terminais, super brotamento na ponta do ramo ortotrópico, além de morte de raízes e queda de flores, refletindo em menor produção de grãos pelas plantas (Carvalho et al., 2010).

Em uma pesquisa realizada por Fernandes et al. (2012) em Araguari/MG, o uso de diferentes fontes de $B$ aplicadas de forma parcelada via foliar ou aplicação única no solo, promoveu um aumento de 28 a 59\% na produtividade, em função das fontes e doses utilizadas.

As deficiências nutricionais podem ser avaliadas e evitadas principalmente quando há resultado de análise química do solo confiável, podendo a interpretação levar ao manejo correto da adubação com macro e micronutrientes. Além da análise química do solo, a diagnose foliar pode fornecer diagnóstico preciso sobre a nutrição das plantas, podendo avaliar se o manejo da adubação está correto ou identificar possíveis deficiências ou excessos nutricionais.

\section{Formas de absorção de boro pelas plantas}

$\mathrm{Na}$ solução do solo o $\mathrm{B}$ está em um equilíbrio dependente do $\mathrm{pH}$ entre ácido bórico e íon borato, com pKa de 9,24, sendo a forma $\mathrm{H}_{3} \mathrm{BO}_{3}$ predominante em solos ácidos ou neutros e a forma $\mathrm{B}(\mathrm{OH})^{-}$predominante em solos alcalinos (WIMMER; EICHERT, 2013). Dessa forma, em regiões 
tropicais o $\mathrm{B}$ permanece na forma de $\mathrm{H}_{3} \mathrm{BO}_{3}$ carga zero, sendo facilmente lixiviado para camadas profundas do solo.

O principal mecanismo de absorção de B pelas raízes das plantas é o fluxo de massa, movimentando em distâncias maiores para próximo das raízes, podendo ser aplicado a lanço, pulverizado em área total ou utilizado no sulco de semeadura para culturas anuais e perenes.

A principal reserva de $B$ no solo é a matéria orgânica, estando totalmente disponível para as plantas, sendo também a principal forma de reter este micronutriente no solo. Segundo Prado (2008) em solos arenosos, com elevadas precipitações, alto grau de intemperismo, e baixa quantidade de matéria orgânica, podem ocorrer elevada lixiviação do nutriente, levando a possível deficiência de $B$.

\section{Dinâmica de boro no solo}

A dinâmica do B no solo é influenciada por diversos fatores como, $\mathrm{pH}$, precipitação, temperatura, textura e manejo da matéria orgânica (BOLOGNA, 2003; YAMADA, 2016).

Em trabalho realizado por Sako et al. (2016) analisando os teores de macro e micronutrientes que estavam presentes em até $1,0 \mathrm{~m}$ de profundidade, para lavouras de soja que obtiveram produtividade acima de 70 sacas ha ${ }^{-1}$, observou-se que na camada $0-20 \mathrm{~cm}$ o teor mínimo e máximo de $B$ foi de 0,8 e $1,1 \mathrm{mg} \mathrm{dm}^{-3}$, na camada de $20-40 \mathrm{~cm}$, teores de 0,6 e 0,8 $\mathrm{mg} \mathrm{dm}^{-3}$, camada de $40-60 \mathrm{~cm}$ teores de 0,4 e $0,9 \mathrm{mg} \mathrm{dm}^{-3}$, camada de 80 $100 \mathrm{~cm}$ teores de 0,3 e $0,9 \mathrm{mg} \mathrm{dm}^{-3}$, destacando elevada movimentação em todo o perfil do solo.

Um aspecto que merece destaque na movimentação de B no perfil são os valores de pH. Em estudo realizada por Sá e Ernani (2013), a elevação do $\mathrm{pH}$ para $6,0 \mathrm{em}$ solo com $79 \%$ de argila, reduziu de forma expressiva a quantidade de $\mathrm{B}$ lixiviado na camada de $0-30 \mathrm{~cm}$, quando comparado ao solo que não foi corrigido com calcário ( $\mathrm{pH} \mathrm{4,8).}$ 
Este efeito do $\mathrm{pH}$ é explicado pelo valor da $\mathrm{pKa}$ do $\mathrm{H}_{3} \mathrm{BO}_{3}$, valor este de 9,24 (HU, 1997). Conforme vai se elevando os valores do $\mathrm{pH}$ próximo a 9,24, ocorre predomínio de $\mathrm{B}(\mathrm{OH}) 4^{-}$, aumentando sua adsorção nas argilas e consequentemente, diminui o processo de perda por lixiviação (GOLDBERG et al., 1993).

\section{Fatores relacionados com a dinâmica de boro no solo}

Em todo o mundo, o micronutriente que apresenta maior probabilidade de deficiência é o $\mathrm{B}$. Isso se deve a alta capacidade de lixiviação que pode sofrer, principalmente em solos arenoso e de baixa CTC (LUKASZEWSKI; BLEVINS, 1996).

Biggar e Fireman (1960) concluíram que ocorreu maior retenção de B em solos argilosos quando comparado a solos arenosos, isso se deve ao fato da maior capacidade de adsorção nas argilas quando comparado a solos de textura arenosa. Page e Cooper (1955) demonstraram que ocorreu perda por lixiviação de aproximadamente $85 \%$ de B, quando aplicado 125 $\mathrm{mm}$ de água em solo arenoso. Os valores de $\mathrm{pH}$ influenciam de forma direta na dinâmica de $\mathrm{B}$ no solo, isso se deve em virtude da transformação de $\mathrm{H}_{3} \mathrm{BO}_{3}$ para $\mathrm{B}(\mathrm{OH})_{4}^{-}$quando o $\mathrm{pH}$ está mais próximo de 9,24.

Em uma pesquisa realizada por Soares, Alleoni e Casagrande (2005), em solos tropicais intemperizados, a elevação do valor de $\mathrm{pH}$ favoreceu a adsorção de B na camada de $0-20 \mathrm{~cm}$ e em subsuperfície (camada de 1,0-1,3 m) em três solos estudados: Latossolo Vermelho, Latossolo Amarelo e Nitossolo, demonstrando efeito benéfico do aumento do $\mathrm{pH}$ na maior retenção de B no solo.

Quanto aos minerais presentes no solo, suas influências na dinâmica de B são muito importantes. Os óxidos de alumínio adsorvem mais $B$ do que os óxidos de ferro. Dessa forma, em pH 6,0, a adsorção de óxidos de alumínio foi 20 vezes maior quando comparado ao óxido de ferro, Figura 1 e 2 (GOLDBERG; GLAUBIG, 1985; apud GOLDBERG, 1997). 
Para minerais de argila, a adsorção de B segue a seguinte ordem; caulinita<montmorilonita<ilita, sendo a adsorção máxima quando se eleva os valores de $\mathrm{pH}$ entre 8 e 9, Figura 3 (HIGSTON, 1996; apud GOLDBERG, 1997).

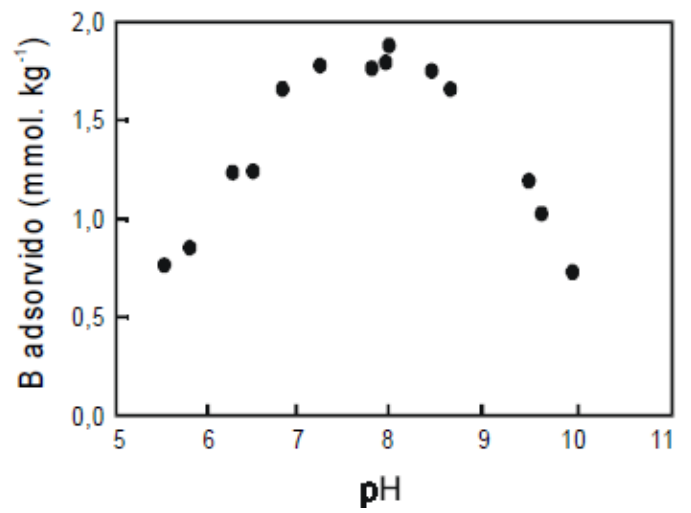

Figura 1. Adsorção de B pelos óxidos de ferro, em solução contendo 5 mg L${ }^{1}$ de B. Fonte: Goldberg e Glaubig (1985); apud Goldberg (1997).

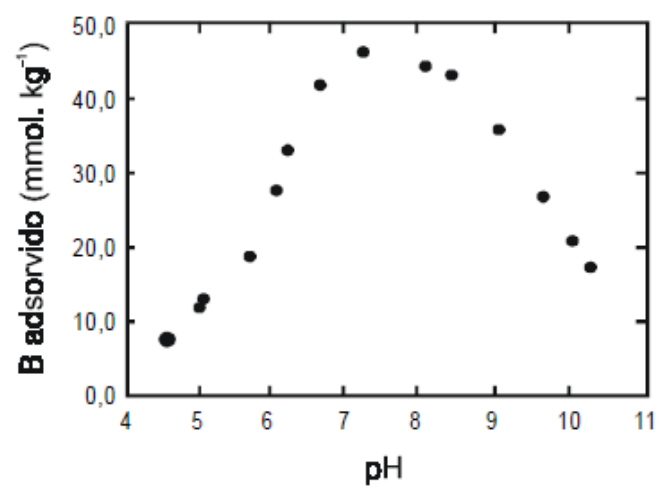

Figura 2. Adsorção de B pelos óxidos de alumínio, em solução contendo 5 mg L'-1 de B. Fonte: Goldberg e Glaubig (1985); apud Goldberg (1997).

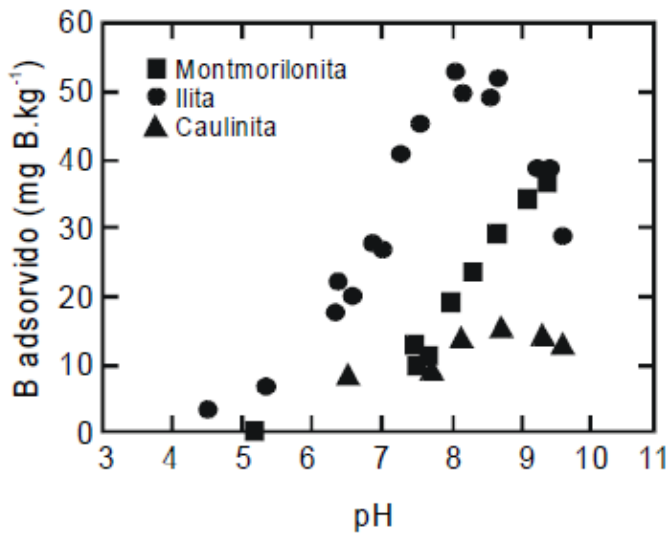

Figura 3. Adsorção de B pelas argilas em solução de $2 \mathrm{mg} \mathrm{L}^{-1}$ de B. Fonte: Goldberg e Glaubig (1985); apud Goldberg (1997). 
A precipitação é um fator que merece atenção em relação a dinâmica de B. Em trabalho realizado por Silvestrim (2001), observou-se que no ano de 2009/2010, em que choveu $22 \%$ a mais do que a média histórica na região de Campos Gerais/PR, ocorreu maior lixiviação do B abaixo de 40 $\mathrm{cm}$ de solo, demonstrando que quando ocorrem elevadas precipitações as taxas de lixiviação de $\mathrm{B}$ podem ser maiores.

A matéria orgânica é uma das principais formas de retenção de $B$ no solo (AZEVEDO et al., 2001), ela apresenta a capacidade de formar ligações com $\mathrm{B}(\mathrm{OH}) 4^{-}$, servindo com uma reserva do nutriente para plantas, dessa forma um manejo que visa o aumento da matéria orgânica através do plantio direto, correção do solo, rotação de culturas e resíduos orgânicos, são fatores que favorecem o aumento de níveis de B no solo.

A dinâmica do $B$ no solo é bastante complexa e entender esses fatores, colaboram para o manejo desse micronutriente. Fatores como o material de origem, textura e precipitação não podem ser controlados dentro do manejo, mas $\mathrm{opH}$ e matéria orgânica são parâmetros que podem ser manejados dentro do sistema de produção, visando aumento da eficiência de absorção de $B$ pelas culturas.

\section{Estimativas de lixiviação de boro no perfil}

As perdas por lixiviação de B nas camadas do solo podem ser diferentes e isso está ligado a fatores como: textura, tipo de solo, precipitação, matéria orgânica, material de origem, fontes de B utilizado e dose aplicada. Em um estudo realizado por Correia et al. (2016), avaliandose três fontes de boro (Ulexita, Ulexita + turfa e boráx) as perdas por lixiviação aumentaram conforme o aumento da dose de $B$, eles também concluíram que no Latossolo Vermelho-Amarelo ocorreu menor lixiviação de B quando comparado ao Planossolo Háplico. Em relação as perdas estimadas de B observadas no trabalho de Correia et al. (2015), utilizandose a dose intermediária de $4,0 \mathrm{~kg} \mathrm{ha}^{-1}$ de $\mathrm{B}$, a perda foi de $4,5 \%$ e $18 \%$ no Latossolo Vermelho-Amarelo e Planossolo Háplico, respectivamente. 
Avaliando as perdas por lixiviação em três tipos de solo e três fontes de B (ácido bórico, ulexita e hidroboracita em termofosfato), Abreu et al. (2015) estimaram perdas médias de 70\%, 43\% e 11\%, respectivamente, em relação as fontes, em um Neossolo Quartzarênico órtico típico e no Latossolo Vermelho eutroférrico típico.

Analisando o comportamento de três fontes de B (ácido bórico, ulexita e fritas) em três tipos de solos arenoso, argiloso e orgânico, Abreu et al. (2004) concluíram que as perdas de B no solo arenoso atingiram 90\% para o ácido bórico e ulexita, com uma diferença de que o B proveniente do ácido bórico lixiviou de forma mais rápida e acentuada. Para o solo argiloso, perdas de $80 \%$ foram verificadas para ácido bórico, 70\% para ulexita e 5\% para as fritas. Para o solo orgânico, perdas de $90 \%$ foram constatadas para ácido bórico e ulexita e 10\% para as fritas, destacando que nesse estudo o ácido bórico teve lixiviação em porcentagem maior com uma menor quantidade de água fornecida nos três solos estudados.

\section{Classificação dos teores de boro no solo e no tecido vegetal}

A classificação do teor dos nutrientes no solo é de grande importância para a tomada de decisão visando sua correção, dessa forma, uma abordagem criteriosa das classificações dos níveis de B no solo para as culturas da soja, milho, feijão e café é bastante pertinente. Para a cultura da soja, milho e feijão, segundo a Embrapa (2009) o teor de B é classificado de acordo com a Tabela 2, sendo o extrator água quente. Segundo Zavaschi (2018), a classificação dos teores de B no solo para culturas anuais pode ser feita de acordo com a Tabela 3, sendo o extrator água quente.

\section{Tabela 2. Classificação de boro no solo para culturas anuais.}

\begin{tabular}{ccc}
\hline Cultura & Teor de B no solo ppm & Classificação \\
\hline Soja/milho/feijão & $\leq 0,15$ & Muito baixo \\
Soja/milho/feijão & $0,16-0,35$ & Baixo \\
Soja/milho/feijão & $0,36-0,60$ & Médio \\
Soja/milho/feijão & $0,61-0,90$ & Bom \\
Soja/milho/feijão & $>0,91$ & Alto \\
\hline
\end{tabular}

Fonte: Embrapa (2009). 
Tabela 3. Classificação de boro no solo para culturas anuais.

\begin{tabular}{ccc}
\hline Cultura & Teor de B no solo ppm & Classificação \\
\hline Soja/milho/feijão & $\leq 0,20$ & Muito baixo \\
Soja/milho/feijão & $0,21-0,40$ & Baixo \\
Soja/milho/feijão & $0,41-0,70$ & Médio \\
Soja/milho/feijão & $0,71-0,90$ & Adequado \\
Soja/milho/feijão & $>0,91$ & Alto \\
\hline
\end{tabular}

Fonte: Zavaschi (2018).

Para a cultura do café, segundo Mesquita et al. (2016) e a Fundação Procafé (2015) os teores de B podem ser classificados de acordo com as Tabelas 4 e 5, sendo o extrator água quente. Pode-se notar que a Fundação Procafé utiliza valores de referência com parâmetros mais altos para o micronutriente $\mathrm{B}$.

Tabela 4. Classificação de boro no solo para o café.

\begin{tabular}{ccc}
\hline Cultura & Teor de B no solo ppm & Classificação \\
\hline Café & $\leq 0,20$ & Muito baixo \\
Café & $0,21-0,40$ & Médio \\
Café & $0,41-0,60$ & Adequado \\
Café & $>0,61$ & Alto \\
\hline
\end{tabular}

Fonte: Mesquita et al. (2016).

Tabela 5. Classificação de boro no solo para o café.

\begin{tabular}{ccc}
\hline Cultura & Teor de B no solo ppm & Classificação \\
\hline Café & $\leq 0,50$ & Baixo \\
Café & $0,51-1,00$ & Médio \\
Café & $>1,00$ & Alto \\
\hline
\end{tabular}

Fonte: Fundação Procafé (2015).

A classificação do teor de B no solo auxilia na tomada de decisão, pois, se os valores são considerados adequados ou alto, a probabilidade de resposta a adubação com $B$ será pequena quando atingir esses níveis no solo.

A diagnose foliar é uma excelente ferramenta para avaliar a absorção dos nutrientes pelas plantas e, assim, avaliar se as adubações estão sendo satisfatórias para atender a demanda das plantas ou verificar possíveis deficiências ou excessos nutricionais. 
Para a cultura da soja a recomendação para a coleta de folha para avaliação do estado nutricional é no estádio fenológico de $R_{1}-R_{2}$, coletandose $03^{\circ}$ ou $4^{\circ}$ trifólio a partir do ápice para a base das plantas, sem pecíolo, 30 folhas por talhão. Os teores foliares para a soja são considerados deficientes quando for menor que $37 \mathrm{mg} \mathrm{kg}^{-1}$, suficiente entre $37-56 \mathrm{mg} \mathrm{kg}^{-1}$ e alto maior que $56 \mathrm{mg} \mathrm{kg}^{-1}$ (EMBRAPA, 2009).

Para a cultura do milho a coleta de folhas para a diagnose foliar necessita ser no estádio fenológico $R_{2}$, coletando-se a folha oposta e abaixo da espiga, 30 folhas por talhão (MALAVOLTA et al., 1997). Os teores foliares de B para milho são adequados quando estão entre 15 e $20 \mathrm{mg} \mathrm{kg}^{-1}$ (BULL, 1993; apud COELHO, 2009). Em relação ao feijoeiro, a coleta de folhas para a diagnose foliar é realizada no estádio fenológico $R_{6}$, coletando-se de 30 a 40 trifólios do terço médio (ROSOLEM; MARUBAYASHI, 1994). Os teores adequados para B em feijão são de 30 a $60 \mathrm{mg} \mathrm{kg}^{-1}$ (EMBRAPA, 1998; apud VITTI et al., 2017).

Para o café o momento correto da coleta de folhas é na fase de chumbinho coletando na altura média da planta o $3^{\circ}$ ou $4^{\circ}$ nó do ramo plagiotrópico, um par de cada lado da planta, coletando de 40 a 50 pares de folhas por talhão (FUNDAÇÃO PROCAFÉ, 2015). O teor foliar suficiente de B para o café é de 40 a $80 \mathrm{mg} \mathrm{kg}^{-1}$ (FUNDAÇÃO PROCAFÉ, 2015).

\section{Fontes de boro na agricultura e suas características}

Ácido bórico - $\left(\mathrm{H}_{3} \mathrm{BO}_{3}\right)$ : apresenta solubilidade de $60 \mathrm{~g} \mathrm{~L}^{-1}$ à temperatura de $20 \stackrel{\circ}{\circ}$, apresentando concentração de $17-18 \%$ de B. Esta fonte é totalmente disponível para as plantas, podendo sofrer elevada lixiviação em função da textura do solo, precipitação e teor de matéria orgânica, geralmente é utilizado em aplicações via solo, no momento da dessecação pré-plantio ou aplicado na projeção da copa de culturas perenes como o café, também pode ser utilizado via folha.

Colemanita - $\mathrm{Ca}_{2} \mathrm{~B}_{6} \mathrm{O}_{11} .5 \mathrm{H}_{2} \mathrm{O}$ : fonte de borato de cálcio de baixa solubilidade e liberação lenta para as plantas, a concentração de B varia de $10-16 \%$ de acordo com o grau de hidratação. Esta fonte em virtude de sua 
liberação mais lenta para as plantas pode ser uma alternativa para aplicação em solos arenosos e de textura média visando reduzir as taxas de lixiviação. Como sua solubilidade é pequena necessita aplicar a lanço ou ser utilizado em mistura com fertilizantes para o plantio.

Ulexita - $\mathrm{NaCaB}_{5} \mathrm{O}_{6} .5 \mathrm{H}_{2} \mathrm{O}$ : fonte borato de cálcio e sódio, apresenta baixa solubilidade em água e disponibiliza o $\mathrm{B}$ de forma lenta para o solo, variando conforme sua granulometria (BYERS et al., 2001). Apresenta concentração de $10-15 \%$ de B e cálcio de 12-14\%, é utilizado em aplicação a lanço para culturas anuais, em área total, ou misturado em adubos formulados, para culturas perenes pode ser fornecido na projeção da copa. É uma outra opção em casos solos arenosos ou textura média com elevadas precipitações e baixo teor de matéria orgânica, em virtude de sua liberação mais lenta, visando reduzir perdas por lixiviação.

Bórax - $\mathrm{Na}_{2} \mathrm{~B}_{4} \mathrm{O}_{7} .10 \mathrm{H}_{2} \mathrm{O}$ : fonte borato de sódio, apresenta elevada solubilidade, o teor de $B$ varia de $10-15 \%$ e pode ser utilizado no momento da dessecação para culturas anuais ou fornecido para culturas perenes na projeção da copa, ou no momento da aplicação de fungicidas via solo, pode ser utilizado via folha.

Octaborato de Sódio $-\mathrm{Na}_{2} \mathrm{~B}_{8} \mathrm{O}_{13} .4 \mathrm{H}_{2} \mathrm{O}$ : fonte de alta solubilidade, 10 g $100 \mathrm{ml}^{-1}$ de água a $20^{\circ} \mathrm{C}$, o teor de boro varia entre $20-21 \%$, pode utilizado no momento da dessecação para culturas anuais ou fornecido para culturas perenes na projeção da copa, ou no momento da aplicação de fungicidas via solo, pode ser utilizado via folha.

Termofosfato com Boro: geralmente é adicionado colemanita, aumentando sua solubilidade com o tratamento térmico dos fosfatos. Essa fonte apresenta $17 \%$ de $\mathrm{P}_{2} \mathrm{O}_{5}$ total, $20 \%$ de $\mathrm{Ca}, 7 \%$ de $\mathrm{Mg}, 0,4 \%$ de $\mathrm{B}, 23 \%$ de $\mathrm{SiO}_{2}$ (BOLOGNA, 2003). A aplicação é realizada em área total visando a adubação de correção do fósforo e juntamente a adubação com boro, antes de iniciar a semeadura ou plantio, momento de preparo do solo e correções. 


\section{Modos de aplicação de boro para culturas anuais e perenes}

Para as culturas anuais como a soja, milho e feijão, o B pode ser aplicado no momento da dessecação de pré-plantio, em mistura com herbicidas. Nessa modalidade de aplicação, é necessário escolher fontes de alta solubilidade, como por exemplo, o ácido bórico, bórax ou octaborato de sódio, sendo mais recomendada para solos corrigidos, com textura argilosa ( $>35 \%$ de argila) visando reduzir as perdas por lixiviação, pois todas as fontes possuem disponibilidade rápida para o fornecimento de $\mathrm{H}_{3} \mathrm{BO}_{3}$ para as plantas. É importante destacar que dependendo do volume de calda utilizado na dessecação, deve-se atentar ao índice solubilidade de cada fonte, visando reduzir problemas operacionais no momento da aplicação, a fonte com maior índice de solubilidade é o octaborato de sódio com $100 \mathrm{~g} \mathrm{~L}^{-1}$ de água a $20^{\circ} \mathrm{C}$ (VITTI, 2019).

Outra forma de aplicação de B para culturas anuais é a utilização de formulações de N-P-K que contenha B. É preferível utilizar fontes de baixa solubilidade em mistura com fertilizantes (FANCELLI, 2010).

A aplicação a lanço em área total é outra modalidade de aplicação. Essa forma favorece a correção do B no solo, pois as doses acabam sendo maiores para a aplicação a lanço, sem causar toxidade nas culturas, podendo utilizar fontes como ácido bórico, ulexita, colemanita. A escolha da fonte de $\mathrm{B}$ pode ser baseada na textura do solo, regime hídrico de cada região, pH e matéria orgânica.

Para a cultura do café, o fornecimento de B para as plantas pode ser realizado no momento da aplicação de fungicidas/inseticidas via solo (outubro-novembro), escolhendo fontes de alta solubilidade como ácido bórico ou octaborato de sódio (MATIELLO; FACUNDES, 2016). Outra maneira é a aplicação na projeção da copa com B via ulexita.

Outra forma de fornecer o B para o café é utilizando adubos formulados que contenha boro em sua composição, assim em cada adubação se fornece parte da dose de boro. 
Estratégias de adubação com boro nas culturas da soja, milho, feijão e café

As interpretações de análises químicas do solo, juntamente com as características físicas, especialmente textura, servem para a tomada de decisão em relação a adubação boratada, e sua correção é de extrema importância para a obtenção de aumento de produtividade (SANTINI et al., 2016).

As adubações com B devem ser realizadas buscando atingir teores acima do nível crítico, com o objetivo de correção de B no solo e aumento da produtividade (YAMADA, 2016). Nesse sentido, para a cultura da soja as adubações podem ser realizadas com as seguintes dosagens dependendo do teor no solo, como ilustra a Tabela 6.

Tabela 6. Recomendação da dose de B de acordo com o teor no solo para a cultura da soja, milho e feijão.

\begin{tabular}{ccc}
\hline Teor de B no solo ppm & Classificação & Dose kg ha \\
\hline$\leq 0,20$ & Muito baixo & 2,0 \\
$0,21-0,40$ & Baixo & 1,5 \\
$0,41-0,70$ & Médio & 1,0 \\
$0,71-0,90$ & Bom & 0,5 \\
$>0,91$ & Alto & 0,00 \\
\hline
\end{tabular}

Fonte: Broch e Ranno (2011); Vitti (2019).

De acordo com a Tabela 6, caso seja utilizado B na semeadura, não ultrapassar mais que $0,5 \mathrm{~kg} \mathrm{ha}^{-1}$ de B (VITTI, 2019). Nessa modalidade de aplicação, utilizar fonte de liberação lenta como a ulexita ou colemanita, complementando o restante da dose de $\mathrm{B}$, caso tenha necessidade, no momento da dessecação, ou em aplicação à lanço antes da semeadura. Para a aplicação em dessecação, recomenda-se aplicação da fonte octaborato de sódio devido a sua maior solubilidade quando comparado ao ácido bórico.

Para cultura do café em formação e produção, a recomendação de interpretação e doses estão presentes na Tabela 3. 
Tabela 7. Recomendação da dose de B de acordo com o teor no solo para a cultura do café em produção.

\begin{tabular}{ccc}
\hline Teor de B no solo ppm & Classificação & Dose $\mathrm{kg} \mathrm{ha}^{-1}$ \\
\hline$\leq 0,20$ & Baixo & 3 \\
$0,21-0,40$ & Médio & 2 \\
$0,41-0,60$ & Bom & 1 \\
$>0,60$ & Alto & 0 \\
\hline
\end{tabular}

Fonte: Ribeiro et al. (1999)

Para o cafeeiro em produção, pode-se optar pela adubação na projeção da copa utilizando fontes de B ou em mistura com os adubos formulados. Pode-se também utilizar no momento da aplicação com fungicida/inseticida o B misturado com os defensivos, sendo que fontes de maior solubilidade como o ácido bórico ou octaborato de sódio devem ser priorizadas visando facilitar as misturas e diluição (MATIELLO; FAGUNDES, 2016).

Para solos arenosos ou textura média, pode-se utilizar fontes de solubilidade mais lenta, aplicadas na projeção da copa, visando reduzir os processos de lixiviação.

Para o cafeeiro no momento do plantio ou formação, utilizar B quando o teor for baixo, aplicando na cova ou sulco de plantio 0,6 $\mathrm{g}_{\text {planta-1 }}{ }^{-1}$ de B (GUIMARÃES et al., 1999). Nessa situação, utilizar fontes de baixa solubilidade visando disponibilizar o nutriente de forma lenta para as plantas.

Relação da correção do solo em profundidade com a nutrição de boro para as culturas

A relação da correção do solo em profundidade com a capacidade das plantas em absorver água e nutrientes de maneira mais eficiente, torna o sistema de produção cada vez mais produtivo e rentável. Apesar de ocorrer processos de lixiviação de alguns nutrientes para camadas mais profundas, se o sistema radicular estiver explorando grandes volumes de solo em profundidade, o problema da lixiviação pode ser bastante amenizado, em virtude da absorção pelas raízes. 
Em uma pesquisa realizada por Sako et al. (2016) na região Sul, Sudeste e Centro Oeste do país visando analisar quais fatores impactam na produtividade da soja, os autores concluíram que para obter produtividades acima de 70 sacas ha-1 $^{-1}$ um dos fatores foi atingir teores de $B$ acima de 0,5 $\mathrm{mg} \mathrm{dm}^{-3} \mathrm{em}$ uma profundidade de até $1,0 \mathrm{~m}$.

Segundo Yamada (2016), para a correção de B no perfil do solo na profundidade de até $1,0 \mathrm{~m}$, sugere-se como fórmula empírica o seguinte: $\mathrm{B}$ $\left(\mathrm{kg} \mathrm{ha}^{-1}\right)=\%$ argila / 10, aplicando uma dose máxima de 2,0 kg ha-1 em cada safra.

Para que as raízes consigam se desenvolver em profundidade é necessário realizar algumas estratégias que visem a correção do solo, destacando como ferramentas para essa correção em profundidade: calagem, correção dos teores de fósforo e potássio, uso de gesso seguindo os critérios técnicos, rotação de culturas, uso de plantas de cobertura, manejo do impedimento físico e adoção do sistema plantio direto. Estas séries de práticas impactam de forma positiva nas melhorias das condições químicas, físicas e biológicas dos solos (JANDREY, 2019).

\section{Considerações Finais}

A importância da utilização de $B$ na nutrição mineral das plantas vem sendo comprovada com aumento da qualidade e produtividade para diversas culturas. $\mathrm{O}$ entendimento sobre o funcionamento das diversas fontes de $\mathrm{B}$ disponíveis na agricultura permite $\mathrm{O}$ melhor posicionamento dessas tecnologias visando reduzir perdas no sistema por lixiviação ou evitar possíveis sintomas de fitotoxicidade, fato que depende da dose e forma de aplicação. A dinâmica de B no solo é complexa e pode ser alterada com a correção do solo, aumento da matéria orgânica, plantio direto e reposição do micronutriente para as plantas. A correção do solo em profundidade é uma forma de reduzir o impacto da lixiviação do $B$, isto em virtude da maior exploração do sistema radicular, favorecendo o processo de absorção pelas raízes em camadas mais profundas do solo. 


\section{Referências}

ABREU, C.A. et al. Reação e movimentação de boro no solo, aplicado como ulexita, fritas e ácido bórico. Campinas, 2004.

ABREU, C.A. et al. Lixiviação e disponibilidade de boro em função de fontes e características de solos, Natal, XXXV Congresso Brasileiro de Ciência do Solo, 2015.

ARNON, D.I.; STOUT, P. R. The essentiality of certain elements in minute quantity for plants with special reference to copper. Plant Physiology, v. 14, p.371-375, 1939. http://dx.doi.org/10.1104/pp.14.2.371.

AZEVEDO, W.R.; FAQUIN, V.; FERNANDES, L.A. Adsorção de boro em solos de várzea do Sul de Minas Gerais. Pesquisa Agropecuária Brasileira, v. 36, n. 7, p. 957-964, 2001. https://doi.org/10.1590/S0100204X2001000700005.

BIGGAR, J.W., FIREMAN, M. Boron adsorption and release by soils. Soil Science Society of American Proceedings, v. 24, p. 115-20, 1960.

BOLOGNA, I. R. Adubação boratada em pomar de laranja Pêra Rio afetado pela clorese variegada do citros. 2003, 78p. Dissertação (Mestrado) - Escola Superior de Agricultura - "Luiz de Queiroz", Piracicaba, 2003.

BROCH, D.L.; RANNO, S.K. Fertilidade do solo, adubação e nutrição da cultura da soja. Tecnologia e Produção: soja e Milho, 2011.

BRUNS, $H$. Effects of boron foliar fertilization on irrigated soybean (Glycine max L. Merr.) in the Mississippi River Valley Delta of the midsouth, USA. Archives of Agriculture and Environmental Science, v. 2, n. 3, p. 167 169, 2017.

BULL, L. T. Nutrição mineral do milho. In: BÜLL, L. T.; CANTARELLA, H. (Ed.). Cultura do milho: fatores que afetam a produtividade. Piracicaba: Associação Brasileira para Pesquisa da Potassa e do Fosfato, 1993. p. 63145.

CAKMAK, I.; KURZ, H.; MARSCHNER, H. Short -term effects of boron, germanium and high light intensity on membrane permeability in boron deficient leaves of sunflower. Physiologia Plantarum, v. 21, p.11-18, 1995.

CARVALHO, J.G.; GUIMARÃES, R.J.; BASTOS, A.R.R.; BALIZA, D.P.; GONTIJO, R.A.N. Sintomas de desordens nutricionais em cafeeiro. In: GUIMARÃES, R.J.; MENDES, A.N.G.; BALIZA, D.P (Eds). Semiologia do cafeeiro. Editora UFLA, Lavras, MG, Brasil, 2010. p. 31-59.

COHEN, M.S.; LEPPER, R. Effects of boro on cell elongation and division in squash roots. Plant Physiology, v.59, p. 884-887, 1977. 
CORREIA, R. O. S. R. et al. Solubilidade e mobilidade de fertilizantes boratados em condições controladas. In: MARTINS, A. L. S. M. et al. (ed). Seminário Pibic Embrapa Solos 2015/2016. Rio de Janeiro: Embrapa Solos, 2016. p. 29-32.

COSTA, L. F. S. et al. Aplicação de boro em feijoeiro e aspectos microbiológicos do solo. Revista Mirante, v. 7, n. 2, p. 157-167, 2014.

EMBRAPA. Deficiências nutricionais na cultura do feijoeiro e suas correções. Goiânia, 1996, 40p.

EMBRAPA. Micronutrientes. 2009. Disponível em: <https://www.agencia.cnptia.embrapa.br/gestor/feijao/arvore/CONTAG01_20 _237200483743.html>. Acesso em 10 de janeiro 2019.

FANCELLI, A.L. Boas práticas para o uso de fertilizantes na cultura do milho. IPNI - Informações Agronômicas, v 131: 1:15, 2010.

FERNANDES, A.L.T. et al. Fontes de boro na produção do cafeeiro em solos de cerrado, v.8, n. 15, p. 954, 2012.

FLORES, R. A. et al. Grain Yield of Phaseolus vulgaris in a function of application of boron in soil. Journal of Soil Science and Plant Nutrition, v. 18, n. 1, p.144-156, 2018. http://dx.doi.org/10.4067/S071895162018005000701.

FUNDAÇÃO PROCAFÉ. Padrões referenciais. 2018. Disponível em: $<$ http://www.fundacaoprocafe.com.br/laboratorio/solos-e-folhas/padroesreferenciais>. Acesso em 02 de fevereiro, 2018.

GAUCH, H.G.; DUGGER, JR. The role of boron in the translocation of sugar. Plant Physiology, v. 28, n. 3, p. 457-466, 1953. http://dx.doi.org/10.1104/pp.28.3.457.

GOLDBERG, S. Chemistry and mineralogy of born in soils. In: GUPTA, U.C. (ed.). Boron and its role in crop production. Boca Raton: CRC Press, 1997. p.3-44.

GOLDBERG, S.; FORSTER, H.S.; HEICK, E.L. Boron adsorption mechanisms on oxides, clay minerals and soils inferred from ionic strength effects. Soil Science Society of American Journal, v. 57, n. 3, p. 704-708, 1993. https://doi.org/10.2136/sssaj1993.03615995005700030013x.

GUIMARÃES, P. T. G. et al. Cafeeiro. In: RIBEIRO, A.C. et al. ed. Recomendações para o uso de corretivos e fertilizantes em Minas Gerais, 5a Aproximação. Viçosa, MG, Comissão de Fertilidade do Solo do Estado de Minas Gerais - CFSEMG. 1999. p.289-302.

HANSEL, F.D.; OLIVEIRA, M.L. Importância dos micronutrientes na cultura da soja no Brasil. Piracicaba, IPNI Brasil, n. 153, 2016, 21 p. 
LABORSOLO. Atenção aos micronutrientes: o Boro. 2015. Disponível em: $<$ https://www.laborsoloacademy.com.br/plantas/atencao-aosmicronutrientes-o-boro/>. Acesso em: 20 de setembro 2019.

$\mathrm{HU}, \mathrm{H}$. Isolation and characterization of soluble boron complexes in higher plants. The mechanism of phloem mobility of boron. Plant Physiology, v. 113, p. 649-655, 1997. https://doi.org/10.1104/pp.113.2.649.

JANDREY, D.B. Compactação de solos agrícolas. Pioneer sementes. http://www.pioneersementes.com.br/blog/99/compactacao-de-solosagricolas. Acesso 22 de setembro de 2019.

KOBAYASHI, M.; OHNO, K.; MATOH, T. Boron nutrition of cultured tobacco BY-2 cells. II. Characterization of the boron-polysaccharide complex. Plant Cell Physiology, v. 38, p. 676-683, 1997.

LOUÉ, A. Oligo-éléments en agriculture. Antibes: Nathan, 1993. 557 p.

LUKASZEWSKI, K. M.; BLEVINS, D. G. Root growth inhibition in boron deficient or aluminum-stressed squash may be a result of impaired ascorbate metabolism. Plant Physiology, v. 112, p. 1135-1140, 1996

MALAVOLTA, E. Manual de nutrição mineral de plantas. Piracicaba: Ceres, 2006. $631 \mathrm{p}$.

MALAVOLTA, E.; VITTI, G. C.; OLIVEIRA, S. A. Metodologia para análise de elemento em material vegetal. In: MALAVOLTA, E.; VITTI, G.C.; OLIVEIRA, S.A. Avaliação do estado nutricional das plantas: princípios e aplicações. 2. ed. Piracicaba: Associação Brasileira para Pesquisa da Potassa e do Fosfato. p. 231-307, 1997.

MATIELLO, J.B.; FAGUNDES, A.V. Uso de boro via drench em cafezais. Clube de Tecnologia Cafeeira, Varginha, 2016.

MENGEL, K.; KIRKBY, E. A. Principles of plant nutrition. Bern: International Potash Institute, 687p. 1987.

MESQUITA, Carlos Magno de et al. Manual do café: manejo de cafezais em produção. Belo Horizonte: EMATER-MG, 2016. 72 p. il.

MORAES, L.A.; MORAES, V.H.F.; MOREIRA, A. Relação entre a flexibilidade do caule de seringueira e a carência de boro. Pesquisa Agropecuária Brasileira, v. 37, n. 10, p. 1431-1436, 2002.

MOZAFAR, A. Effect of boron on ear formation and yield components of two maize (Zea mays L.) hybrids. Journal of Plant Nutrition, v. 10, n. 3, p. 319332, 2008. https://doi.org/10.1080/01904168709363575.

NOGUEIRA, L. M. Doses e modo de aplicação de boro e zinco na cultura do milho. 2016, 67 p. Dissertação (Mestrado em Sistemas de Produção) Universidade Estadual Paulisa, "Júlio de Mesquita Filho" -UNESP, Ilha Solteira, 2016. 
OLIVEIRA, I. P.; ARAÚJO, R. S.; DUTRA, L. G. Nutrição mineral e fixação biológica de nitrogênio. In: ARAÚJO, R. S.; RAVA, C. A.; STONE, L. F.; ZIMMERMANN, M. J. O. (Coord.). Cultura do feijoeiro comum no Brasil. Piracicaba: Associação Brasileira para Pesquisa da Potassa e do Fosfato, 1996, p.182-203.

ORLANDO FILHO, J.; ROSSETO, R.; CASAGRANDE, A.A. Cana-deaçúcar. In: FERREIRA M.E. et al. (Ed). Micronutrientes e elementos tóxicos na agricultura. Jaboticabal: CNPq; Fapesp; Potafos: 355-368, 2001.

PAGE, N. R; COOPER, H. P. Less-soluble boron compounds for correcting boron nutritional deficiencies. Journal of Agricultural Food Chemicals, v. 3., n. 3, p. 222-231, 1955.

PETRA, M. Marschner's mineral nutrition of higher plants. 3.ed. 2012, $651 p$.

PRADO, R. M. Nutrição de plantas. São Paulo; Editora Unesp, 2008. 407p.

RERKASEM, B. et al. Grain set failure in boron deficient wheat. Plant and Soil, v.155, p.309-312, 1993.

RIAZ, M. et al. Boron alleviates the aluminum toxicity in trifoliate Orange by regulating antioxidante defense system and reducing root cell injury. Journal of Environmental Management, v. 208, p. 149-158, 2018. https://doi.org/10.1016/j.jenvman.2017.12.008.

RiBeiro, A. C.; Guimarães, P. T. G.; Álvarez V., V. H. (Ed.). Recomendação para o uso de corretivos e fertilizantes em Minas Gerais, 5a aproximação. Viçosa: Comissão de Fertilidade do Solo do Estado de Minas Gerais, 1999. 359p.

ROSOLEM, C.A.; MARUBAYASHI, O.M. Seja o doutor do seu feijoeiro. In: Encarte do Informações Agronômicas, n.68, dezembro 1994. 16p.

SÁ, A.A.; ERNANI, P. R. Boron leaching decreases with increases on soil pH. Revista Brasileira de Ciência do Solo, v. 40, p. 1-7, 2016. https://doi.org/10.1590/18069657rbcs20150008

SAKO, H. et al. Fatores decisivos para se obter produtividade da soja acima de $4.200 \mathrm{~kg} / \mathrm{ha}$. Circular técnica 2, Comitê estratégico Soja Brasil, Sorocaba, 2016, 29p.

SANTINI, J.M.K et al. Adubação boratada na cultura da soja em área de cerrado. XXXV Congresso Brasileiro de Ciência do Solo, 2015, Natal -RN.

SILVESTRIM, F. Dinâmica de boro no solo e planta e sua influência na cultura do milho em dois Latossolos de textura média, 2001, 39p. Dissertação (Mestrado - Ciência do Solo) - Universidade Federal do Paraná, Curitiba, 2001. 
SOARES, M.R.; ALLEONI, L.R.F.; CASAGRANDE, J.C. Parâmetros termodinâmicos de reação de adsorção de boro em solos tropicais altamente intemperizados. Química Nova, v. 28, n. 6, 1014-1022, 2005. http://dx.doi.org/10.1590/S0100-40422005000600016.

VARANDA, M.A.F. et al. Efeitos da aplicação foliar de boro na produtividade de soja na várzea irrigada. Pesquisa Aplicada \& Agrotecnologia, v. 11, n. 2, p. 15-22, 2018. http://dx.doi.org/10.5935/PAeT.V11.N2.02.

VITTI, G.C. Curso de especialização a distância em solos e nutrição de plantas. Piracicaba, 2019. 252 dispositivos:color.

VITTI, G.C.; ZAVASCHI, E.; NETO, A.C. O papel dos micronutrientes na fisiologia e nutrição do feijoeiro. In: FANCELLI, A.L. Feijão Condicionantes da Produtividade. Piracicaba: Pecege, 2017. 6 c. 107-118.

WIMMER, M.A.; EICHERT, T. Review: mechanisms for boron deficiencymediated changes in plant water relations. Plant Science, v. 203-204, p. 25-32, 2013. https://doi.org/10.1016/j.plantsci.2012.12.012.

YAMADA, T. 2016. Síndrome das raízes atrofiadas. Disponível em https://docplayer.com.br/52567382-Sindrome-das-raizes-atrofiadas-iideficiencia-de-boro.html.

ZABINI, A.; CARVALHO, M.; BARBOSA, C. Resposta do cafeeiro a doses de boro via solo na região das matas de minas. $34^{\circ}$ Congresso de Pesquisas Cafeeiras. 2008.

ZAVASCHI. E. Curso de especialização a distância em solos e nutrição de plantas. Piracicaba, 2018. 65 dispositivos, color. 